\title{
An Experimental and Computational Investigation of $n$-Dodecane Ignition and Chemical Kinetics
}

\author{
Darshan M.A. Karwat* \\ Scott W. Wagnon and Jason Y.W. Lai ${ }^{\dagger}$ \\ Margaret S. Wooldridge $\ddagger$ \\ Charles K. Westbrook ${ }^{\S}$
}

Understanding combustion chemistry for long chain $n$-alkanes is important for improving the predictive understanding of these important hydrocarbons. This work focuses on computational and experimental investigations of $n$-dodecane $\left(n-\mathrm{C}_{12} \mathrm{H}_{26}\right)$ reaction kinetics over a range of temperatures and pressures. New ignition data were acquired at low temperatures (750-800 $\mathrm{K})$, moderate pressures (3.25 atm) and approximately stoichiometric equivalence ratios in the University of Michigan rapid compression facility (UM RCF). Modifications to the reaction mechanism for $n$-dodecane developed by Westbrook et al. ${ }^{14}$ were explored for predicting ignition delay times for the UM RCF data and high temperature shock tube data in the literature. The computational and experimental results show that $n$-dodecane ignition is highly sensitive to temperature and pressure conditions, as well as reactant mixture composition, and that the new experimental data are in the negative temperature coefficent region. The computational studies further show that the negative temperature coefficient region shifts to higher temperatures as pressures increase and that $n$-dodecane ignition shows distinct characteristics of two-staged ignition at the lower temperatures and pressures studied.

\section{Introduction}

Large $n$-alkanes are key species in driving the reactivity and chemical kinetics of complex commercial fuel mixtures such as kerosene and diesel. ${ }^{1}$ Fuels such as kerosene are complex mixtures of approximately 1000 hydrocarbons, ${ }^{2}$ of which approximately $25 \%$ are $n$-alkanes (the majority of which are $\mathrm{C}_{11}-\mathrm{C}_{12}$ ), $50 \%$ are branched $i$ - and $c$-alkanes, and $25 \%$ are aromatics. Residual unsaturated hydrocarbons (HC) are also present. ${ }^{3}$ An understanding of the chemical kinetics occurring when these fuels burn is necessary to quantify combustion performance, air pollutant formation pathways, and the sensitivity of these pathways to various thermodynamic states. This

* Graduate Student, AIAA Member, Department of Aerospace Engineering, University of Michigan, Ann Arbor, MI 48109

${ }^{\dagger}$ Graduate Students, Department of Mechanical Engineering, University of Michigan, Ann Arbor, MI 48109

${ }^{\ddagger}$ Arthur F. Thurnau Professor, Departments of Aerospace and Mechanical Engineering, University of Michigan, Ann Arbor, MI 48109

${ }^{\S}$ Research Scientist, Lawrence Livermore National Laboratory, Livermore, CA 94550, USA 
understanding forms a foundation to understand the impacts of perturbing these kinetics by the addition of biofuels or the use of alternative fossil fuel feedstocks. Jet aircraft tests to study the feasibility of blending kerosene-based aviation fuels with various biodiesels and nut oils are already underway. ${ }^{4-6}$ This paper focuses on the chemical kinetics of $n$-dodecane $\left(n-\mathrm{C}_{12} \mathrm{H}_{26}\right)$, at low temperatures and moderate pressures. $n$-Dodecane represents an important reference compound for large $n$-alkanes to understand the reaction kinetics of jet fuels.

Since the seminal paper by Curran et al. ${ }^{7}$ there has been much progress in understanding the chemical kinetics that control the ignition of large $n$-alkanes over low-to-high temperature conditions. Curran et al. identified 25 reaction classes that form the framework for understanding the low-to-high temperature kinetics of large $n$-alkanes. ${ }^{7}$ Additionally, experimental studies - in shock tubes, ${ }^{8-10}$ jet-stirred reactors ${ }^{11,12}$ and rapid compression machines $(\mathrm{RCMs})^{13}$ - have provided important data necessary for quantifying the reactivity and identifying key intermediates, major reaction pathways, major products and undesirable byproducts of large $n$-alkane combustion. These studies have also provided data for validating chemical kinetic mechanisms, the complexities of which are growing tremendously. For example, Westbrook et al. have developed a mechanism $\left(\mathrm{C}_{8}-\mathrm{C}_{16}\right)$ that contains 2116 reactants and 8130 reactions. ${ }^{14}$ Most experimental studies of large $n$ alkane combustion and oxidation have been performed in shock tubes and jet-stirred reactors. ${ }^{8-12}$ The study of large $n$-alkanes in RCMs presents new challenges, particularly given the negative temperature coefficient (NTC) behavior of these fuels.

Large $n$-alkanes with seven carbons and higher are often used to represent the reactivity of more complex, practical fuels like diesel, gasoline and kerosene. $n$-Alkane studies of $\mathrm{C}_{7}$ through $\mathrm{C}_{14}$ show that large $n$-alkane reactivity is similar for similar equivalence ratios, pressures and temperatures, and that ignition becomes faster as pressure increases. ${ }^{10}$ Large $n$-alkanes show significant reactivity at low temperatures due to peroxy-chemistry pathways that result in lowtemperature chain branching and consequently shorter ignition delay times, $\tau_{\text {ign. }}$. Curran et al. ${ }^{7}$ Shen et al. ${ }^{10}$ and Westbrook et al. ${ }^{14}$ provide lucid descriptions of large $n$-alkane chemistry. A brief summary of the dominant reaction pathways is presented here.

At low temperatures $(T \lesssim 900 K)$, fuel consumption occurs via H-atom abstraction from the fuel molecule (forming alkyl radicals, $\mathrm{R}$ ) and addition of $\mathrm{O}_{2}$ molecules to fuel radicals to form $\mathrm{RO}_{2}$ radicals. $\beta$-scission is slow at low temperatures, and therefore alkyl radicals prefer to add $\mathrm{O}_{2}$. ( $\beta$-scission follows $\mathrm{H}$-atom abstraction - the $\mathrm{C}$-C bond one removed from the $\mathrm{C}$ with the missing $\mathrm{H}$ is the weakest bond in the alkyl radical. This bond will break first, resulting in two smaller radicals and one of the radicals becomes an olefin.) Low-temperature combustion is also characterized by the isomerization of $\mathrm{RO}_{2}$ radicals. This forms hydroperoxy-alkyl radicals (QOOH), and subsequent $\beta$-scission leads to smaller olefins and aldehydes. Addition of $\mathrm{O}_{2}$ to QOOH radicals forms a transition-ring complex that isomerizes and decomposes to form ketohydroperoxide and hydroxyl radicals $(\mathrm{OH})$. This is the key chain branching step. This largely influences NTC behavior, where fuel/oxidizer reactivity increases with decreasing temperature. Therefore, transition state rings are very important. Ketohydroperoxide decomposition is slow at low temperatures, and therefore concentrations accumulate. Subsequent decomposition of these species leads to the formation of a carbonyl radical and an $\mathrm{OH}$ radical. The $\mathrm{OH}$ radicals lead to an increase in reactivity of the system, and therefore an increase in ketohydroperoxide decomposition. $\mathrm{RO}_{2}$ radical isomerization is much faster than reaction of $\mathrm{RO}_{2}$ species with hydroperoxy $\left(\mathrm{HO}_{2}\right)$ radicals, the only exception being methylperoxy radical reacting with $\mathrm{HO}_{2}$ radicals. Alkoxy radicals formed through reactions between $\mathrm{RO}_{2}$ radicals decompose quickly to form aldehydes or ketones and an alkyl radical species. 
Aldehydes are generally very reactive, and fuel rich mixtures are more reactive at low temperatures.

At intermediate or moderate temperatures $(T \lesssim 1000 K)$, chain branching also occurs due to $\mathrm{H}_{2} \mathrm{O}_{2}$ decomposition forming $2 \mathrm{OH}$. As mentioned above, the NTC region is largely influenced by the decomposition of transition-ring complexes formed from QOOH radicals. This pathway is strongly pressure dependent. Therefore, $\tau_{\text {ign }}$ often exhibit pressure dependence stronger than $\tau_{\text {ign }} \alpha P^{-1}$ (i.e. $\left.\tau_{\text {ign }} \alpha P^{-a}, a>1\right) .{ }^{10}$ At moderate temperatures, the low-temperature branching reaction pathway competes with the dissociation of QOOH radicals to form different products: olefins and $\mathrm{HO}_{2}$, cyclic ethers and $\mathrm{OH}$, and $\beta$-scission products and alkyl radicals. This moderate temperature pathway results in no radical branching, thus lower reactivity is observed at moderate temperatures, in the NTC regime, than at lower temperatures where $\mathrm{QOOH}+\mathrm{O}_{2}$ is faster than $\mathrm{QOOH}$ decomposition. The competition between these two reactions is strongly pressure dependent. ${ }^{10}$

The NTC region shifts to higher temperatures as pressure is increased. ${ }^{7}$ Ciezki and Adomeit ${ }^{15}$ observed, in a shock tube study of $n$-heptane ignition, that the NTC region moved from 700-900 K at pressures of approximately 13.5 bar to $830-1000 \mathrm{~K}$ at approximately 42 bar. This is due to the influence of pressure on the equilibria of $\mathrm{O}_{2}$ addition to alkyl and QOOH radicals. ${ }^{7}$ For $n$-heptane, a widely used reference compound for diesel, increasing the pressure and equivalence ratio move the NTC region to gradually higher temperatures and reduce its magnitude.

The intermediate radicals and stable species generated during the ignition delay of these large $n$ alkanes have a profound effect on the characteristic pollutant emissions resulting from combustion. In particular, pollutants and volatile organic compounds such as small aromatic and polycyclic aromatic hydrocarbons (PAH) - benzene, toluene, naphthalene, pyrene, styrene, etc. - are produced from small unsaturated $\mathrm{HC}$ such as acetylene, ethene, propene, allene, propyne, and cyclopentadiene, as well as resonantly stabilized HC radical species such as propargyl, allyl, methyl allyl and cyclopentadienyl. Subsequent reactions increase the size of the PAH species, leading eventually to visible soot, with acetylene being a significant growth species. ${ }^{16}$

Given this ever-increasing knowledge of large $n$-alkane combustion chemistry, there remains a dearth of data for individual species such as $n$-dodecane and even fewer speciation data representative of ignition kinetics which can be used to quantify the important reaction pathways and improve our predictive capabilities for large $n$-alkane combustion. For example, Table 1 presents a summary of the conditions of previous experimental work ${ }^{8,10}$ studying $n$-dodecane $\tau_{\text {ign }}$. $\tau_{\text {ign }}$ and speciation data are particularly valuable at conditions directly relevant to combustion applications. Motivated by this demand, the overall objective of this research effort is to improve our quantitative understanding of $n$-dodecane combustion chemistry through computational studies and experimental measurements of key intermediates formed during ignition. We are particularly interested in the formation rates of sentinel species for pollutant emissions, such as acetylene as a precursor for soot particulates. Specifically, the goal of this initial study is to identify the unique challenges presented by studying low vapor pressure fuels in a rapid compression facility. The results of this study will allow us to design experimental procedures to ensure accurate and repeatable results from high-speed gas sampling measurements. This work presents results of both computational and experimental studies of $n$-dodecane ignition conducted in preparation for gas sampling experiments.

\section{Experimental Approach}

The University of Michigan Rapid Compression Facility (UM RCF) was used to conduct these initial ignition experiments for $n$-dodecane. The UM RCF is a unique apparatus that is capable of 
Table 1. Previous $n$-dodecane ignition studies

\begin{tabular}{ccccc} 
Authors & Facility & $\phi$ & Temperature Range $[\mathbf{K}]$ & Pressure Range [atm] \\
\hline Vasu et al. ${ }^{8}$ & Shock tube & 0.5 & $750-1200$ & $18-31$ \\
& & 1 & $725-1150$ & $19-34$ \\
\hline Shen et al. ${ }^{10}$ & Shock tube & 0.5 & $930-1170$ & $11-47$ \\
& & 1 & $875-1220$ & $11-45$
\end{tabular}

investigating fuel combustion chemistry at a broad range of thermodynamic conditions. Previous studies include ester ignition ${ }^{17,18}$ and the study of hydrocarbon combustion intermediates. ${ }^{13}$ Details on performance characterization of the UM RCF can be found in Donovan et al. ${ }^{19,20}$ Briefly, the UM RCF consists of five major components - the driver section, the driven section, the test manifold (or test section), the sabot (a free piston with a tapered nosecone that seals into the test section) and the hydraulic valve system. The entire system can be characterized as a simple free pistoncylinder device. ${ }^{21,22}$ The driver section (with an inner diameter of $154 \mathrm{~mm}$ ) contains high pressure gas that, via a fast-acting globe valve in the hydraulic system, accelerates the sabot, contained in the driven section (2.74 m long, $101.2 \mathrm{~mm}$ inner diameter), to compress a fuel/oxidizer mixture during ignition studies. See Figure 1 for a detailed diagram of the test manifold of the UM RCF.

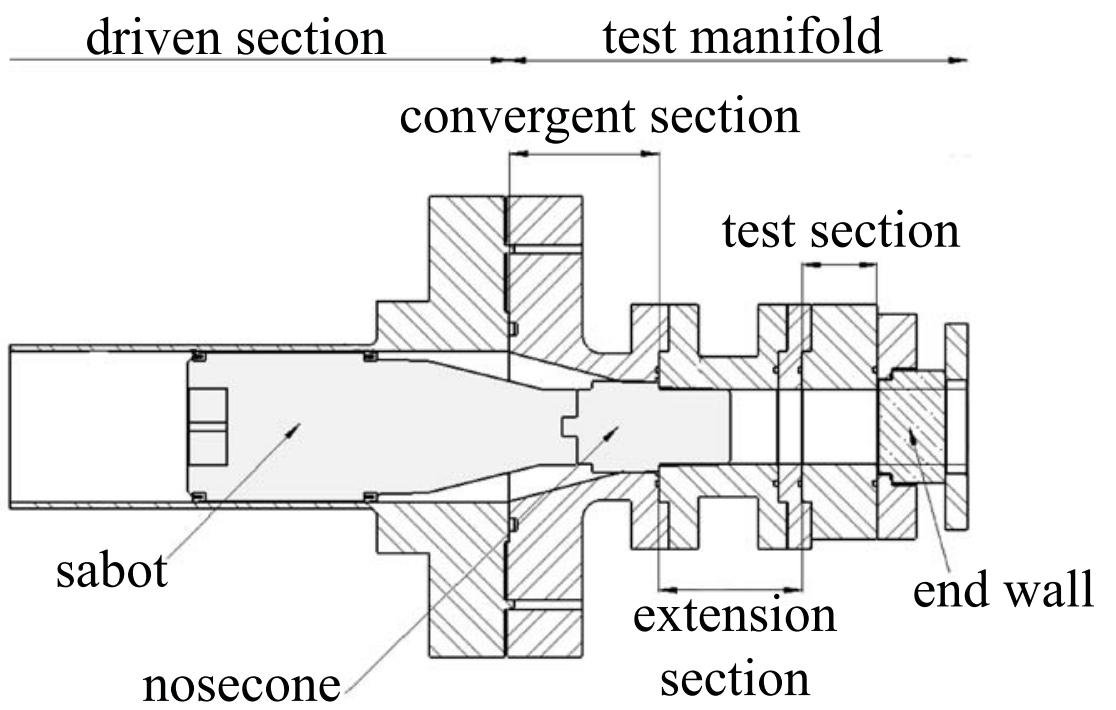

Figure 1. A schematic of the test manifold of the UM RCF. Extension sections can be exchanged to control compression ratios and consequently test temperatures and pressures.

At the end of compression (EOC), the nose cone of the sabot seals the fuel/oxidizer mixture in the test section at specifically designed temperatures and pressures. These specific thermodynamic states can be achieved by varying the compression ratio of the test section, as well as the concentration of inert gases in the test mixture. There is a convergent section that bridges the $101.2 \mathrm{~mm}$ 
inner diameter driven section to the $50.8 \mathrm{~mm}$ inner diameter test section. The colder boundary layer gases are trapped inside the convergent section, thus minimizing the effects on the gases sealed in the test section. At a given pressure and temperature after the EOC, the fuel/oxidizer mixture in the test section autoignites after a period defined as the ignition delay time $\left(\tau_{\text {ign }}\right)$.

Fuel/oxidizer mixtures can be prepared manometrically using a capacitance diaphragm gauge (Varian CeramiCel VCMT12TFA), either in a mixing tank that is connected to the UM RCF, or directly in the driven and test sections of the UM RCF. The pressure in the test section is monitored using a piezoelectric transducer (Kistler 6041AX4) and charge amplifier (Kistler 5010B). The pressure time history is used to determine $\tau_{\text {ign }}$ for each experiment. A transparent end wall provides optical access for end-view imaging, and a transparent cylindrical section provides optical access for side-view imaging using a high-speed camera. High-speed end-view videos of the combustion phenomena were acquired in this study using a Vision Research Phantom v7.1 high-speed color digital camera with a fast $50 \mathrm{~mm}$ lens (f/0.95, Navitar) as well as a c-mount extension tube to optimize chemiluminescent emission capture. All videos were acquired at 23,000 frames per second (fps). Please refer to Walton et al. ${ }^{23}$ for a more detailed description of the imaging procedure.

Ignition and chemical kinetic experiments performed using the $\mathrm{UM} \mathrm{RCF}^{18,21-23}$ have studied high vapor pressure fuels, such as short-chain methyl esters, $n$-heptane and iso-octane. In order to study the ignition and chemical kinetics of low vapor pressure fuels such as $n$-dodecane, and to increase the range of operating conditions of the UM RCF, a controlled heating system was developed for this study. The driven section of the UM RCF was heated using custom heaters (HEATCON) rated to $0.4 \mathrm{~W} / \mathrm{cm}^{2}$. The mixing manifold was heated using silicone rubber extruded heating tapes (HTS/Amptek) rated to $0.7 \mathrm{~W} / \mathrm{cm}^{2}$. The test section was heated using a heavy insulated heating tape (AMOX) rated to $2 \mathrm{~W} / \mathrm{cm}^{2}$. A magnetically-stirred mixing tank was fabricated for this study, and was heated using custom heaters (HEATCON) rated to $0.8 \mathrm{~W} / \mathrm{cm}^{2}$. Temperatures were controlled using a PID control system implementing solid state relays and a data acquisition system (National Instruments NI 9401 and NI 9211). Temperatures on the inner walls of the driven section and test section for these experiments were maintained to $348 \mathrm{~K} \pm 1 \mathrm{~K}$, and temperatures on the mixing manifold and the heated mixing tank were maintained at $373 \mathrm{~K}$ $\pm 1 \mathrm{~K}$. Several experiments were performed using $n$-butanol and iso-octane on the mixing tank to ensure consistency with previously obtained and published experimental results. The temperatures on the inner walls of the driven section were uniform, with the only gradient occurring at the heavy flange on which the test section is mounted. Here, the temperatures decreased to approximately $328 \mathrm{~K}$. Based on this constraint, fuel/oxidizer mixtures were prepared to contain less fuel than the vapor pressure of the $n$-dodecane at $328 \mathrm{~K}$.

$n$-Dodecane/oxidizer mixtures with an equivalence ratio $(\phi)$ of approximately one, targeted EOC pressures of $3.25 \mathrm{~atm}$, and targeted EOC temperatures of $750 \mathrm{~K}$ were prepared using anhydrous $n$-dodecane (Sigma-Aldrich, purum, $>99.0 \%$ GC grade), and ultra-high purity $\mathrm{O}_{2}(99.993 \%)$, $\mathrm{N}_{2}(99.999 \%)$, and laser-grade $\mathrm{CO}_{2}(99.995 \%)$ (Cryogenic Gases, Detroit). For this study, $\phi$ is defined (Equation 1) as

$$
\phi=\frac{\chi_{n \text {-dod }} / \chi_{O_{2}}}{\left(\chi_{n-\text { dod }} / \chi_{O_{2}}\right)_{\text {stoich }}} .
$$

The dilution of the fuel/oxidizer mixture was targeted as 5.64 for all experiments. Mixtures were prepared in the heated, magnetically-stirred mixing tank, and were allowed to mix for approximately 
one hour prior to use.

\section{Computational Approach}

The chemical kinetic mechanism used to study $n$-dodecane ignition kinetics was an updated version of the mechanism developed by Westbrook et al. ${ }^{14}$ to study the the combustion of large $n$-alkanes, $\mathrm{C}_{8}$ through $\mathrm{C}_{16}$. Updates include incorporation of a new $\mathrm{C}_{1}-\mathrm{C}_{4}$ sub-mechanism ${ }^{24}$ and detailed sub-mechanisms for the isomers of linear pentene and hexene. ${ }^{25}$ This updated mechanism contains 2209 species, with 8446 reactions. Two modeling approaches were used in this study - 1) a constant-volume, closed, homogeneous zero-dimensional simulation, and 2) an approach which models the compression process in the UM RCF. All simulations were performed using the CHEMKIN ${ }^{\circledR}$ software. In the constant-volume approach, the initial conditions of the fuel/oxidizer mixture were approximately the targeted EOC conditions during experiments. In order to study computationally the compression of the fuel/oxidizer mixture in the UM RCF, a volume profile was developed that represented the stroke of the sabot in the driven section. This volume profile was used with the zero-dimensional, closed, homogeneous solver in to determine the ignition properties of the mixture. The initial conditions of the fuel/oxidizer mixture at the start of compression (SOC) were typical initial conditions used in the UM RCF experiments. The stroke of the sabot lasts for $145 \mathrm{~ms}$ from SOC to the EOC, during which the fuel/oxidizer is assumed to be compressed isentropically. Heat losses were neglected in all of the simulations.

\section{Results and Discussion}

Several computations were performed to study the effects on the ignition properties of $n$ dodecane. Specifically, a range of pressures, temperatures, composition of diluents and the compresssion process were considered. The initial conditions and mixtures used as inputs into a zerodimensional CHEMKIN ${ }^{\circledR}$ model with the volume profile and time history representing the stroke of the UM RCF are shown in Table 2. All volume-profile simulations(\#1-\#4) performed were for stoichiometric $n$-dodecane $/ \mathrm{O}_{2}$ mixtures, with inert $/ \mathrm{O}_{2}$ ratios of 5.64 , the same mixtures used in thel UM RCF experiments.

Figure 2 shows the results of simulation \#1, for a targeted EOC temperature of $747 \mathrm{~K}$. Time $t=$ 0 corresponds to EOC, after which the volume is constant. The figure presents the simulation results for the temperature and the fraction of $n$-dodecane that has been consumed, both as functions of time following EOC. During most of the compression stroke, the rates of temperature and pressure rise are negligible, and the fractional fuel consumed is close to zero. Only during the last $10 \mathrm{~ms}$ of the stroke do the temperature and pressure rise significantly; the maximum rate of pressure rise, $\mathrm{d} P / \mathrm{d} t$, during compression (not shown in the figure) occurs during the last $10 \mathrm{~ms}$ of the compression process. For simulation \#1, the first stage of a classical two-stage ignition begins 1.7 $\mathrm{ms}$ after EOC. The first stage ignition raises the temperature by nearly $100 \mathrm{~K}$ to a value close to 850 $\mathrm{K}$, after which the temperature becomes nearly constant in time for approximately the next $20 \mathrm{~ms}$. The fractional fuel consumption curve shows that nearly $90 \%$ of the $n$-dodecane is consumed in this first stage; low-temperature reaction is very rapid at about $750 \mathrm{~K}$, with lots of low-temperature chain branching occuring via the alkylperoxy radical isomerization reaction pathways described earlier. The rapid reaction comes nearly to a complete stop at about $850 \mathrm{~K}$, and the simulations indicate that at about $3.7 \mathrm{~atm}$ and $870 \mathrm{~K}$, the addition reactions of $\mathrm{O}_{2}$ molecules to alkyl and

6 of 16

American Institute of Aeronautics and Astronautics 
Table 2. A summary of initial conditions and mixture compositions used as inputs into a zerodimensional CHEMKIN ${ }^{\mathbb{R}}$ model with a volume profile, and results

\begin{tabular}{|c|c|c|c|c|c|c|c|}
\hline $\begin{array}{c}\text { Simulation } \\
\#\end{array}$ & $\begin{array}{c}\text { Target } \\
\text { EOC } \\
T[\mathbf{K}]\end{array}$ & $\begin{array}{c}\text { Target } \\
\text { EOC } \\
P[\text { atm }]\end{array}$ & $T_{0}[\mathbf{K}]$ & \multicolumn{2}{|c|}{$P_{0}[\mathbf{a t m}]$} & $\begin{array}{c}\text { Simulated } \\
\text { EOC } \\
T[K]\end{array}$ & $\begin{array}{c}\text { Simulated } \\
\text { EOC } \\
P[\mathbf{a t m}]\end{array}$ \\
\hline 1 & 747 & 3.25 & 348 & & 474 & 747 & 3.25 \\
\hline 2 & 760 & 3.25 & 348 & & 466 & 760 & 3.25 \\
\hline 3 & 800 & 3.25 & 348 & & 442 & 833 & 3.38 \\
\hline 4 & 850 & 3.25 & 348 & & 417 & 884 & 3.38 \\
\hline $\begin{array}{c}\text { Simulation } \\
\#\end{array}$ & $\chi_{n-d o d}$ & $\chi \boldsymbol{O}_{2}$ & $\chi \mathrm{CO}_{2}$ & $\chi_{N_{2}}$ & $\tau_{\text {ign }}$ & $\begin{array}{r}{[\mathrm{ms}]} \\
\text { Rea } \\
\text { consu } \\
\text { com }\end{array}$ & $\begin{array}{l}\text { tion/fuel } \\
\text { ned during } \\
\text { pression? }\end{array}$ \\
\hline 1 & 0.0081 & 0.1494 & 0.8425 & 0 & & 9 & $x$ \\
\hline 2 & 0.0081 & 0.1494 & 0.7836 & 0.0590 & & .3 & $x$ \\
\hline 3 & 0.0081 & 0.1494 & 0.6117 & 0.2309 & & .2 & $\checkmark$ \\
\hline 4 & 0.0081 & 0.1494 & 0.4381 & 0.4044 & & .7 & $\checkmark$ \\
\hline
\end{tabular}

QOOH radicals have shifted significantly in the direction of dissociation back to the radicals and $\mathrm{O}_{2}$, thereby shutting off the low-temperature ignition kinetics. It is very important to realize that, even with $90 \%$ consumption of the fuel, rather little of this fuel has been converted completely to $\mathrm{H}_{2} \mathrm{O}$ and $\mathrm{CO}_{2}$; the great majority of the $\mathrm{C}$ and $\mathrm{H}$ atoms remain in the form of incompletely oxidized intermediate species, with considerable amounts of large olefins, aldehydes, ketones and other species that must still be oxidized to complete the overall reaction of the initial fuel. Even with $90 \%$ fuel consumption, the temperature of the reacting gas mixture has still increased by only approximately $100 \mathrm{~K}$ out of a total temperature increase that will eventually become as much as nearly $1500 \mathrm{~K}$.

The next stage in the overall ignition is a very slow increase in temperature and pressure as slow oxidation occurs. Between $870 \mathrm{~K}$ and about $1000 \mathrm{~K}$, there are essentially no reaction sequences in the hydrocarbon kinetics that provide significant amounts of chain branching; consequently, there is no opportunity for rapid reaction. At approximately $1000 \mathrm{~K}$ arrives the next chain branching opportunity, where $\mathrm{H}_{2} \mathrm{O}_{2}$ decomposes into two $\mathrm{OH}$ radicals, as noted above and by Westbrook. ${ }^{26}$ In Figure 2, note that the end of the slow reaction period occurs when the temperature has reached a value close to $1000 \mathrm{~K}$, where the rates of temperature and pressure rise increase rapidly, approximately $29 \mathrm{~ms}$ after EOC. This second ignition phase, driven by decomposition of $\mathrm{H}_{2} \mathrm{O}_{2}$, develops rapidly into the final chain branching, ignition phase that does not begin until most or all of the $\mathrm{H}_{2} \mathrm{O}_{2}$ is consumed. The final stage of ignition is driven by the reaction between $\mathrm{H}$ atoms and $\mathrm{O}_{2}$ molecules, $\mathrm{H}+\mathrm{O}_{2}=\mathrm{O}+\mathrm{OH}$. The transition from the $\mathrm{H}_{2} \mathrm{O}_{2}$ decomposition phase into the $\mathrm{H}+$ $\mathrm{O}_{2}=\mathrm{O}+\mathrm{OH}$ phase is so rapid that it cannot be seen in Figure 2, and this combined period of very rapid reaction converts all of the remaining hydrocarbon species into final products $\mathrm{H}_{2} \mathrm{O}$ and 


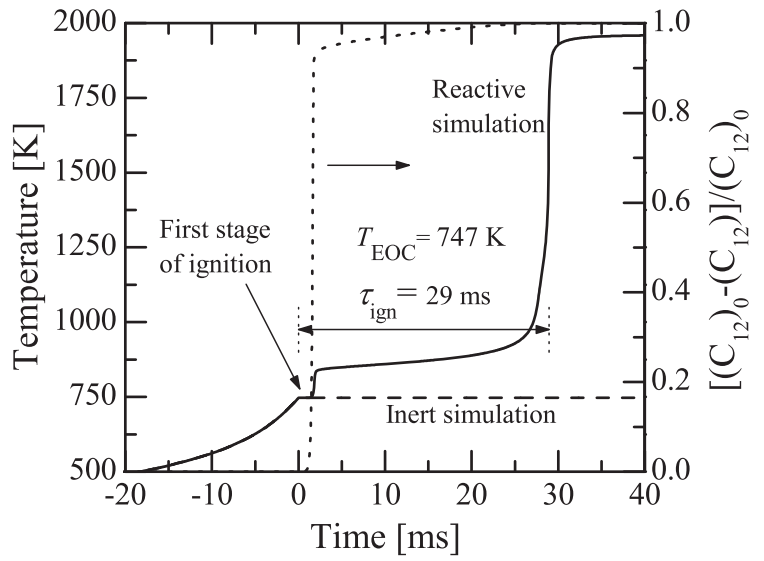

Figure 2. Results for simulation \#1. The overall $\tau_{\text {ign }}$ was computed to be approximately $29 \mathrm{~ms}$.

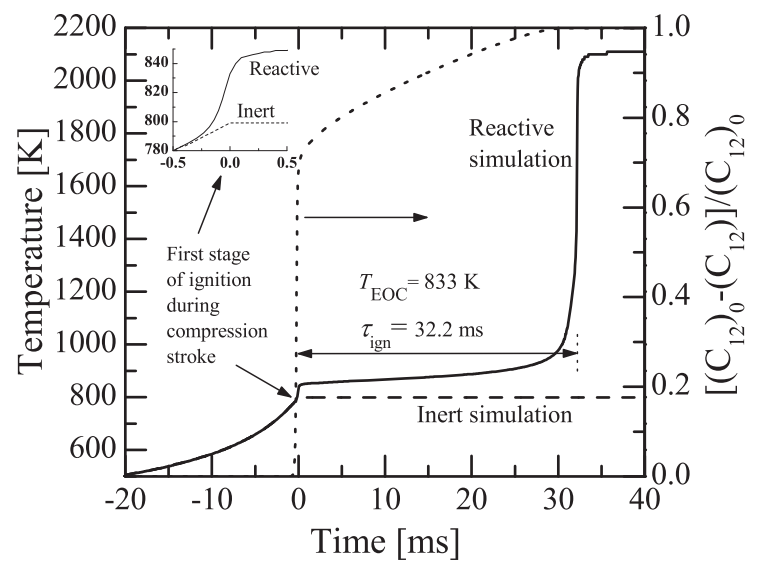

Figure 4. Results for simulation \#3. The overall $\tau_{\text {ign }}$ was computed to be approximately $32.2 \mathrm{~ms}$.

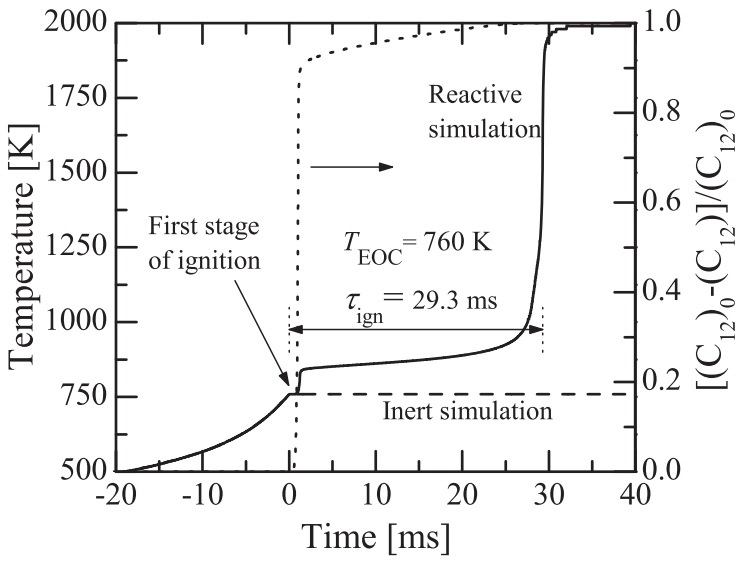

Figure 3. Results for simulation \#2. The overall $\tau_{\text {ign }}$ was computed to be approximately $29.3 \mathrm{~ms}$.

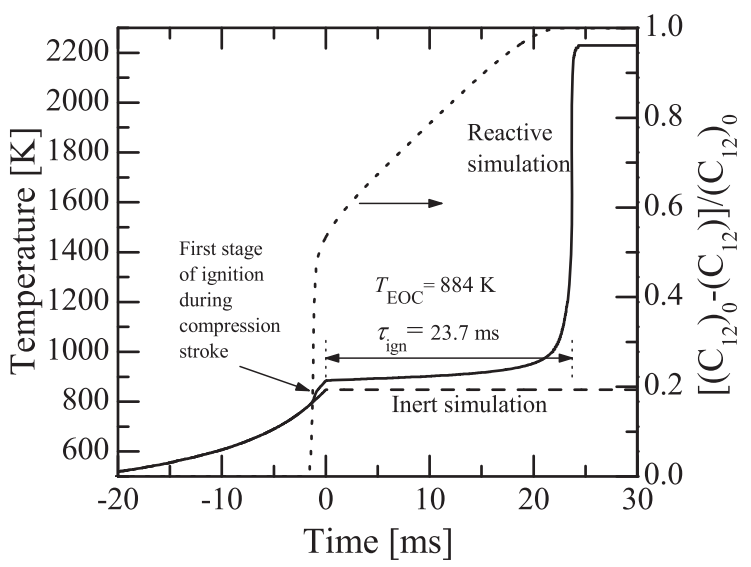

Figure 5. Results for simulation \#4. The overall $\tau_{\text {ign }}$ was computed to be approximately $23.7 \mathrm{~ms}$.

$\mathrm{CO}_{2}$.

A simulation of an inert experiment with the same initial conditions as simulation\#1 was also performed to quantify differences in the EOC conditions as a function of fuel decomposition during compression, essentially to determine whether or not the compression process can be considered isentropic. As noted earlier, in simulation\#1, $n$-dodecane starts decomposing only after EOC, and is almost completely consumed by the first stage of ignition, after which the there is a very gradual consumption of the remaining parent fuel. The same can be observed in Figure 3, which depicts the results of simulation \#2, with a targeted EOC temperature of $760 \mathrm{~K}$. The first stage of ignition occurs $1.2 \mathrm{~ms}$ after EOC, and the second stage of ignition occurs $29.3 \mathrm{~ms}$ after EOC. However, simulation \#3, for a targeted EOC temperature of $800 \mathrm{~K}$, seen in Figure 4, shows a deviation from the isentropic inert simulation starting $0.2 \mathrm{~ms}$ before EOC. Indeed, the EOC temperature is approximately $833 \mathrm{~K}$, with the first stage of ignition occuring right at EOC (within $0.5 \mathrm{~ms}$ ). It is observed that more than $50 \%$ of the $n$-dodecane is consumed at this point. The same is the case for 
simulation \#4, seen in Figure 5, with a deviation from an isentropic compression process occuring $1.5 \mathrm{~ms}$ before EOC.

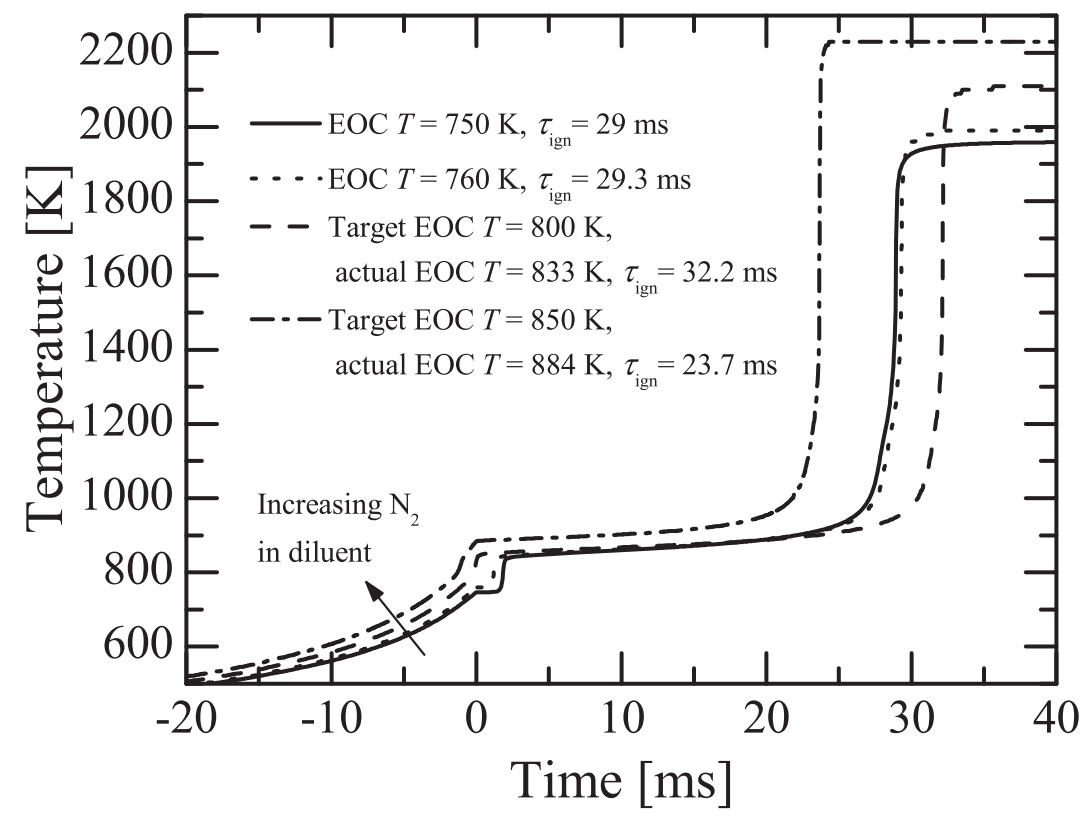

Figure 6. A comparison of temperature time histories for simulations \#1-4.

Like other large $n$-alkanes, $n$-dodecane exhibits significant NTC behavior in the temperature range $700 \mathrm{~K}<T<875 \mathrm{~K}$, as is noted by Westbrook et al. ${ }^{14}$ This is depicted clearly in Figure 6 , which shows the temperature time histories of simulations \#1-4 superimposed. $\tau_{\text {ign }}$ increases from $750 \mathrm{~K}$ to $800 \mathrm{~K}$ (target), and then decreases to below that for $750 \mathrm{~K}$ at $850 \mathrm{~K}$ (target). (One important point to note is that the differences in temperature time histories seen prior to EOC is due to the increasing amounts of $\mathrm{N}_{2}$ and decreasing amounts of $\mathrm{CO}_{2}$ in the diluent, so as to achieve the target EOC conditions. This is precisely how experiments would be designed for the UM RCF. The differences are not due to increased reaction during compression.) The NTC region is precisely the temperature region where we are studying the ignition kinetics of $n$-dodecane. The increased reactivity of $n$-dodecane at low temperatures as compared to higher temperatures poses a potential concern for experimental studies in an RCF, as a non-negligible amount of time is spent at lower temperatures during the compression process.

Figure 7 shows the pressure time-history and still images (extracted from the high-speed imaging sequence) of a typical experiment conducted to study $n$-dodecane ignition kinetics. For each experiment, the effective test conditions were determined using the same methods as in previous UM RCF experiments, ${ }^{18,21-23}$ and were based on the pressure time-history from each experiment, although this may require some modification, as will be discussed later. The effective pressure $\left(P_{\text {eff }}\right)$ was defined (Equation 2) as the time-integrated average pressure from the maximum pressure $\left(P_{\max }\right)$ at the end of compression to the first local maximum of rate of pressure rise $\left(\mathrm{d} P / \mathrm{d} t_{\max }\right)$, 


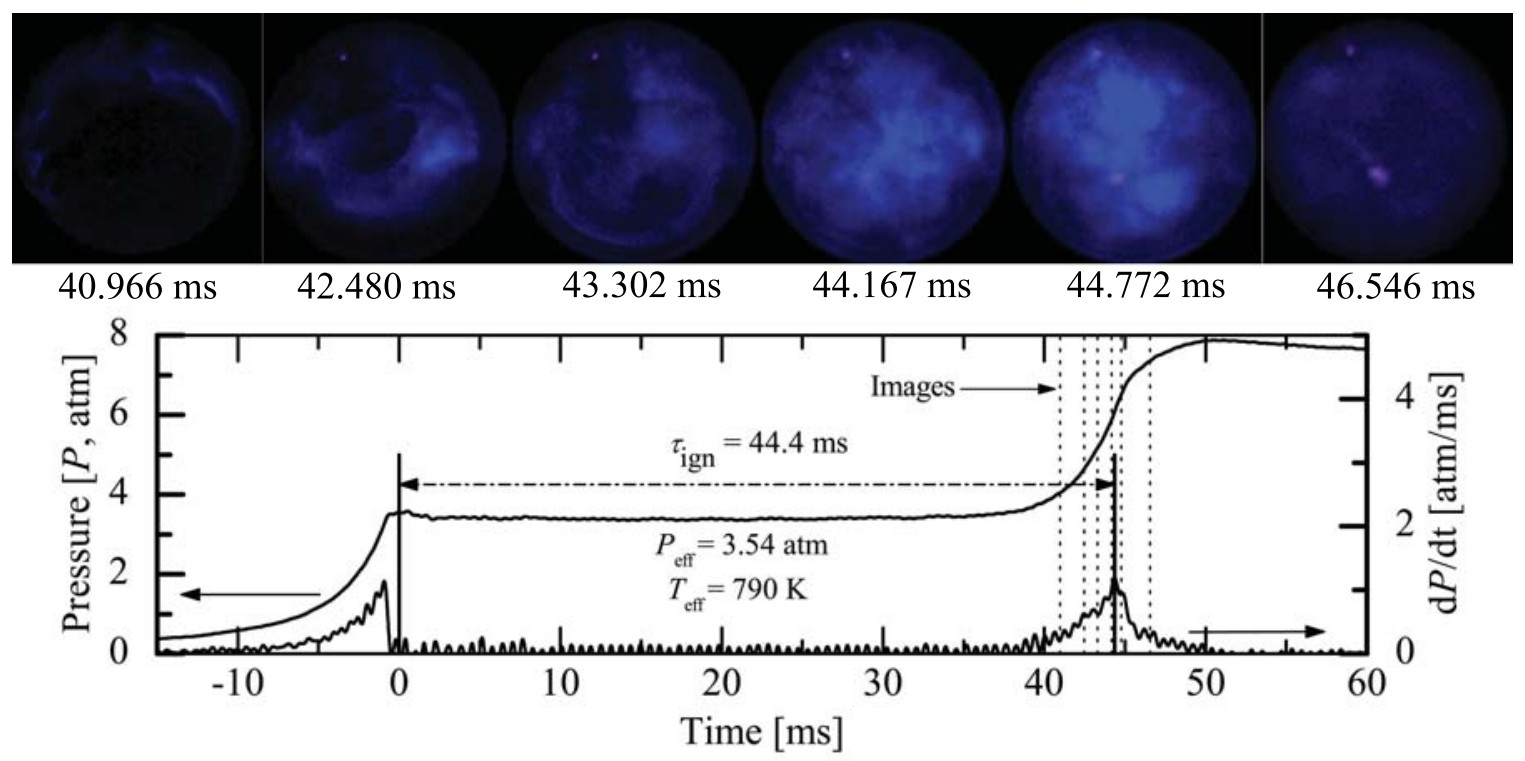

Figure 7. Results for a typical $n$-dodecane ignition experiment with $P_{\text {eff }}=3.54$ atm, $T_{\text {eff }}=790 \mathrm{~K}$, $\phi=0.99$, Inert $/ \mathrm{O}_{2}=\mathbf{5 . 6 6}$ and $\tau_{\text {ign }}=44.4 \mathrm{~ms}$. The lower panel shows the pressure $(P)$ in the test section and the rate of pressure rise $(\mathrm{d} P / \mathrm{d} t)$. EOC corresponds to a time of $\mathrm{t}=0 \mathrm{~ms}$. The upper panel shows still images (end view) acquired at 23,000 fps of the chemiluminescence in the test section corresponding to various times during ignition (color adjusted for clarity).

$$
P_{\text {eff }}=\frac{1}{t_{\mathrm{d} P / \mathrm{dt}_{\max }}-t_{P_{\max }}} \int_{t_{P_{\max }}}^{t_{\mathrm{d} P / \mathrm{dt}_{\max }}} P d t .
$$

The effective temperature for each experiment was determined using $P_{\text {eff }}$ and numerical integration of the isentropic relation (Equation 3),

$$
\int_{T_{0}}^{T_{\mathrm{eff}}} \frac{\gamma}{\gamma-1} d \ln (T)=\ln \left(\frac{P_{\mathrm{eff}}}{P_{0}}\right),
$$

where $P_{0}$ is the initial charge pressure, $T_{0}$ is the initial temperature (typically between 347 and $349 \mathrm{~K}), \gamma$ and is the temperature-dependent ratio of the specific heats of the unreacted test gas mixture (determined using the NASA thermodynamic data base ${ }^{27}$ ). $\tau_{\text {ign }}$ are defined currently as the time between EOC and $\mathrm{d} P / \mathrm{d} t_{\max }$.

Reaction during compression and heat losses during compression can invalidate the assumption of isentropic compression; however, neither effects are considered significant for these experiments, as discussed earlier. The heat losses in the test section are proportional to the thermal diffusivity, $\alpha$ (calculated using Equation 4),

$$
\alpha=\frac{k}{\rho c_{p}}
$$

of the test gas mixtures. Mixtures with higher values of the product $\rho c_{p}$ are less subject to heat losses during $\tau_{\text {ign }}$. $\alpha$ of the EOC test mixtures for these experiments was calculated to be generally 
between $0.88 \times 10^{-5} \mathrm{~m}^{2} / \mathrm{s}$ and $1.14 \times 10^{-5} \mathrm{~m}^{2} / \mathrm{s}$. The lower temperature difference between the test section walls and the EOC temperatures as compared to higher temperature experiments when the walls are left unheated ${ }^{18,21-23}$ further decrease the rate of heat losses for these experiments. We have determined in previous experiments with higher temperature differences and comparable $\alpha$ that the EOC conditions are within $6 \%$ of the values determined by assuming isentropic compression. ${ }^{19}$ Consequently, we expect heat transfer to the test section walls not to be a significant concern for these experiments.

In Figure 7 are depicted the results of an experiment with $P_{\text {eff }}=3.54 \mathrm{~atm}, T_{\text {eff }}=790 \mathrm{~K}, \phi$ $=0.99$, Inert $/ \mathrm{O}_{2}=5.63$ and $\tau_{\text {ign }}=44.43 \mathrm{~ms}$. Shown are the test section pressure $(P), \mathrm{d} P / \mathrm{d} t$ and $\tau_{\text {ign }}$, which is defined as the time between EOC $(t=0 \mathrm{~ms})$ and the local maximum $\mathrm{d} P / \mathrm{d} t$. In the panel above the pressure trace are shown still images from the imaging sequence acquired using the high-speed camera. The first pressure maximum (again, at $t=0 \mathrm{~ms}$ ) results from the essentially isentropic compression process of the test mixture by the sabot of the UM RCF. Pressure fluctuations are seen to quickly damp after EOC and a near uniform pressure is seen until the pressure rises approximately $40 \mathrm{~ms}$ after EOC. This pressure rise corresponds to the first signs of chemiluminescence, as seen in the upper panel in Figure 7. It is observed consistently in the experiments that the first sign of chemiluminescence occurs near the walls of the test section, in the slightly cooler regions of the core gas mixture. Because the reactant mixture is considered well mixed, variations in chemiluminescence are attributed to slight variations in temperature of the test gases. Thus, the chemilluminescence in the annulus region is attributed to the effects of faster kinetics at lower temperatures (i.e. due to NTC behavior) present closer to the wall. Subsequently, chemiluminescence is observed toward the center of the core test gas mixture, with the maximum blue emission occuring at the time the rate of pressure rise reaches a maximum. This point is defined as ignition. An interesting feature observed during $n$-dodecane ignition is that the pressure rise (and chemiluminescence) of ignition is distributed over a longer time, up to 15-30 ms, as compared to other fuels, such as $n$-butanol, which ignite with more rapid rates of pressure rise spanning less than 1-2 ms. Table 3 presents a summary of experimental results presented in this paper, and a compairson between experimental and computationally predicted $\tau_{\text {ign }}$.

Table 3. Summary of the initial $n$-dodecane experimental conditions and results studied.

\begin{tabular}{cccccccc}
$\phi$ & $\chi_{\boldsymbol{n} \text { - } \boldsymbol{d o d}}$ & $\chi_{\boldsymbol{O}_{2}}$ & Inert $/ \mathbf{O}_{2}$ & $P_{\text {eff }}[\mathbf{a t m}]$ & $T_{\text {eff }}[\mathbf{K}]$ & $\tau_{\text {ign }}[\mathbf{m s}]$ meas & $\tau_{\text {ign }}[\mathbf{m s}]$ pred \\
\hline 0.97 & 0.0081 & 0.152 & 5.48 & 2.85 & 710 & 56 & $\approx 28$ \\
0.97 & 0.0081 & 0.149 & 5.65 & 3.33 & 719 & 74 & $\approx 28$ \\
0.97 & 0.0081 & 0.149 & 5.65 & 3.44 & 722 & 59 & $\approx 28$ \\
0.99 & 0.0081 & 0.149 & 5.66 & 3.54 & 790 & 44 & $\approx 36$
\end{tabular}

Figure 8 shows 1) the experimental results obtained using the UM RCF, 2) predictions of constant-volume, zero-dimensional, closed, homogeneous CHEMKIN ${ }^{\circledR}$ simulations of $n$-dodecane $/ \mathrm{O}_{2}$ ignition with $\mathrm{N}_{2}, \mathrm{CO}_{2}$ and Ar as diluents, and 3) simulations \#1-4 presented in Table 2. The thermodynamic conditions targeted in these RCF experiments are well within the NTC region for $n$-dodecane predicted by the mechanism, as seen in Figure 8. The temperatures for simulations \#3 and \#4 are represented as a range, starting from the temperature at which the reactive simulation deviates from the inert simulation and ending at the temperature at EOC (see Figures 4 and 5).

11 of 16 


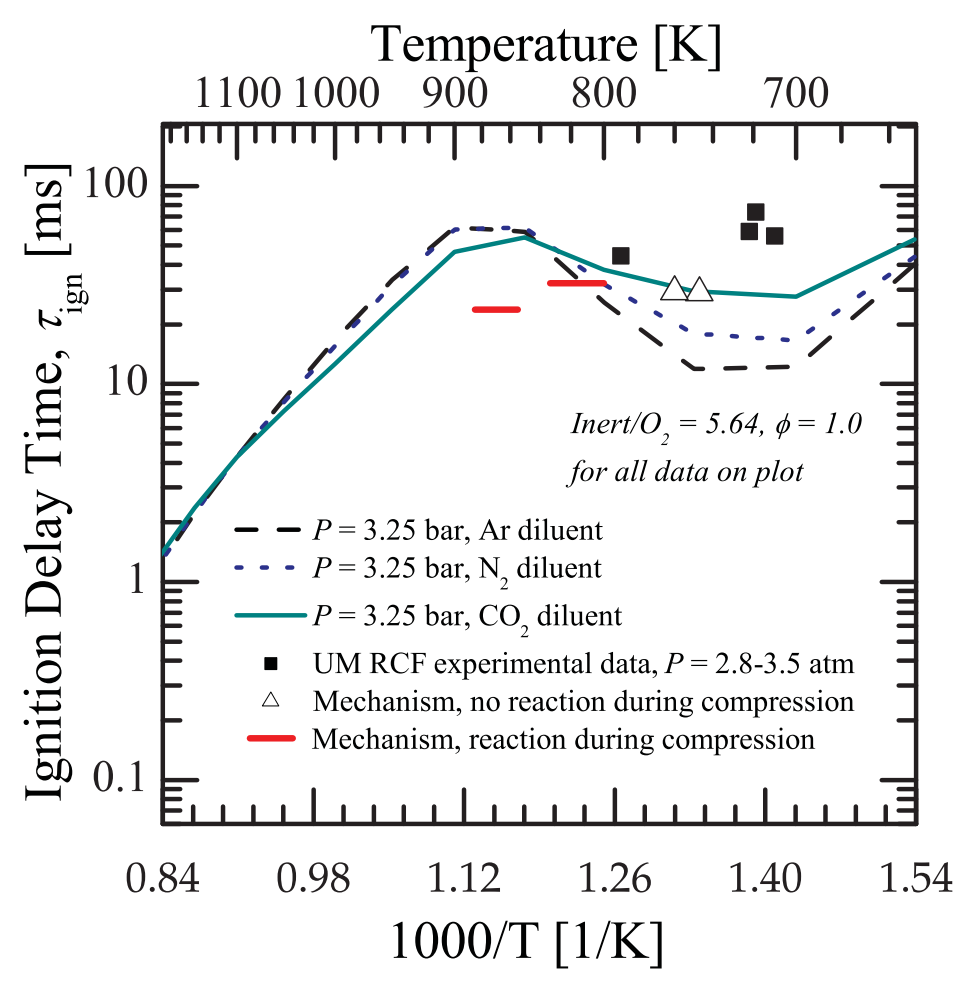

Figure 8. A comparison of $\tau_{\text {ign }}$ mechanism predictions using various diluents and experimental results obtained using the UM RCF presented on an Arrhenius diagram.

Figure 8 shows that $\tau_{\text {ign }}$ is a strong function not only of temperature and pressure (see Figure 9, which depicts changes in $\tau_{\text {ign }}$ as a function of pressure), but also diluent. ${ }^{28}$ The degree of NTC behavior changes as the diluent changes, with a most pronounced NTC response when monatomic Ar is the diluent, less NTC response with the diatomic molecular $\mathrm{N}_{2}$, and the least NTC behavior with the polyatomic $\mathrm{CO}_{2}$ as the diluent. Although the present modeling studies showed some variable response to changes in the composition of the diluent (see Table 2), those diluent variations were intended to vary the EOC gas temperature by varying the $\gamma$ of the reactant mixtures, which is a different effect from that shown in Figure 8. The present experiments covered only a small fraction of the range in EOC temperatures shown in Figure 8, and they used only $\mathrm{CO}_{2}$ as a diluent. As shown in Figure 8, with $\mathrm{CO}_{2}$ as the diluent, the variation in $\tau_{\text {ign }}$ with EOC temperature is relatively small between 650-800 K; consequently, these experiments are considerably more sensitive to variations in pressure and mixture composition than they are to EOC temperature.

For the UM RCF, and for this set of experiments in particular, the primary sources of uncertainty on $\tau_{\text {ign }}$ are the variability in the temperature controller in maintaining the uncompressed fuel/oxidizer mixture at a fixed thermodynamic state (i.e. the initial temperature and pressure of the mixture at the start of each experiment), the accuracy of the pressure transducer used to make the test gas mixtures, and the accuracy of the test section pressure transducer. The temperature controller is currently tuned to maintain the UM RCF within $\pm 1 \mathrm{~K}$ of the set-point temperature. This temperature fluctuation can have potentially a resulting $\pm 3 \mathrm{~K}$ effect on the EOC temperature.

12 of 16 
The temperature fluctuation also has a small but non-negligible effect on the initial fill pressure of the fuel/oxidizer mixture before compression. This pressure fluctuation is between \pm 0.1 Torr, which results in an effect of $\pm 0.01 \mathrm{~atm}$ on the EOC pressure. The compositional uncertainty for each species is \pm 0.01 Torr (equivalent to $\pm 1.3 \times 10^{-5} \mathrm{~atm}$ ), which is the precision of the pressure transducer. The test section pressure transducer introduces an error of $\pm 2 \%$ of the measured pressure, which is also a precision-related error. As noted earlier, the rate of pressure rise was low for these experiments which introduces another source of uncertainty in defining $\tau_{\text {ign }}$ particularly for the low temperature conditions, where ignition spanned $30 \mathrm{~ms}$. An additional source of uncertainty includes potential reaction during compression, which was discussed earlier. The modeling results indicated this is not a concern for the lower temperature conditions studied here $(T<750 \mathrm{~K})$ as no fuel is consumed prior to EOC. The combined effects of these uncertainties on the measured $\tau_{\text {ign }}$ for the $T<750 \mathrm{~K}$ conditions are $\pm 30 \%$.

It is important to understand that the present model calculations do not include the possible effects of thermal non-uniformities, particularly the presence of the thermal boundary layer near the wall of the test section. As noted earlier, the cooler gases near the wall consistently ignite prior to the core region of the test gases, by approximately $5 \mathrm{~ms}$. The ignition of this annulus region will compress the reactants in the core region, increasing the temperature and potentially decelerating reaction in the core, due to the NTC chemistry. A model which captures the radial thermal stratification would be more representative of the RCF experiments. Alternatively, inert experiments (where the $\mathrm{O}_{2}$ is replaced by $\mathrm{N}_{2}$ in the $n$-dodecane mixture) can provide some indirect measures of thermal stratification via pressure time-histories. We are currently exploring both methods as a means to more accurately interpret the experimental results and provide more precise validation of the $n$-dodecane reaction chemistry. For the current work, uncertainty due to thermal stratification is assigned an uncertainty of $\pm 20 \%$ and is treated as an independent source of error. The cumulative uncertainty is therefore $\pm 36 \%$ (determined using the square root of the sum of the squares).

Two interesting shock tube studies of ignition of n-dodecane/air mixtures have appeared recently, ${ }^{8,10}$ as presented in Table 1 . Although these studies were each carried out at pressures considerably higher than the present RCF experiments, we used these shock tube studies to help validate the predictive capabilities of the present kinetic model and to illustrate the effects of reaction pressure on $\tau_{\text {ign }}$ for a large $n$-alkane fuel such as $n$-dodecane. We have compared the experimental results from these shock tube studies with computed $\tau_{\text {ign }}$ using our updated mechanism for $n$-dodecane in Figure 9. Stoichiometric $\tau_{\text {ign }}$ data from Vasu et al. have been scaled as functions of $1 / P$ to 20 bar. Using the same $1 / P$ scaling, data from stoichiometric lower pressure and high pressure experiments by Shen et al. have been scaled to 14 bar and 40 bar, respectively. Model simulations of the present experiments at 3.25 bar are also included in Figure 9. Several important features can be seen. First, the most obvious feature is the decrease in $\tau_{\text {ign }}$ with increasing pressure, over the range from 3.25 to 40 bar. The steady displacement of the NTC region toward higher temperatures with increasing pressure is also evident. The local minimum in $\tau_{\text {ign }}$ in the NTC region moves from about $700 \mathrm{~K}$ at 3.25 bar to nearly $900 \mathrm{~K}$ at 40 bar. Second, the experimental results of Vasu et al. and Shen et al. are consistently quite close to the computed values, although the computed values are slightly longer than the experimental values at temperatures above $1000 \mathrm{~K}$. In addition, the kinetic model shows a somewhat more pronounced NTC behavior than the Vasu et al. experiments. The Shen et al. experiments did not extend to temperatures low enough to show NTC behavior.

13 of 16 


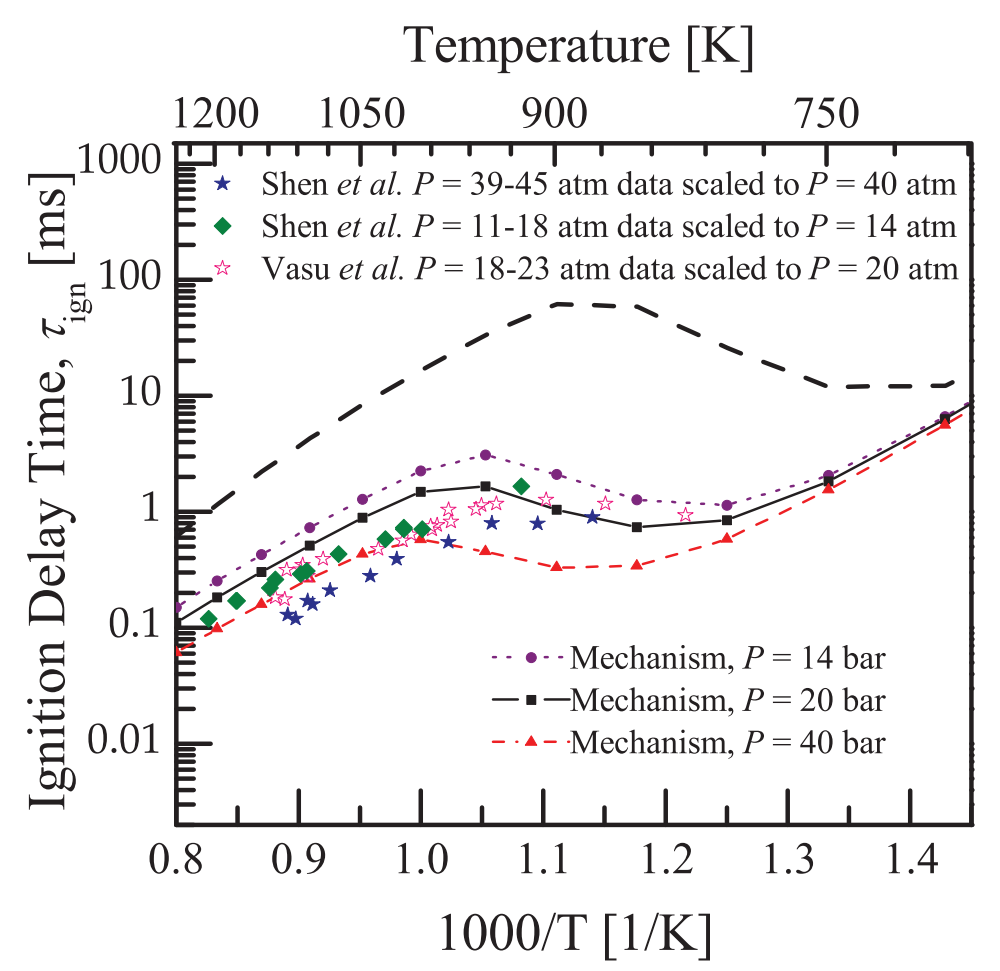

Figure 9. Mechanism redictions of $\tau_{\text {ign }}$ compared to scaled experimental results obtained by Vasu et $a l .{ }^{8}$ and Shen et $a l .{ }^{10}$ These results are compared to mechanism predictions at 3.25 bar (Ar diluent) and UM RCF data (see Figure 8 for legend.)

\section{Conclusions}

The current work presents new experimental data on $n$-dodecane ignition at conditions not previously available in the literature, and new computational results for high and low temperature conditions. The experimental data confirm NTC behavior predicted by large $n$-alkane reaction chemisty for moderate pressure (3.25 atm) and low temperature conditions (750-800 K). The modeling and experimental results of this study indicate $n$-dodecane ignition is highly sensitive to pressure and diluent composition at the NTC conditions studied using the UM RCF. The model predictions are in good agreement with the measured RCF ignition delay times (within a factor of 2-3, where the reaction mechanism predicts faster ignition delay times) and with high temperature shock tube data (also within a factor of 2-3). The modeling results further show the NTC region shifts to higher temperatures at higher pressure. The results of this study increase our confidence in our predictive capabilities for the combustion chemistry of this key long chain $n$-alkane.

\section{Acknowledgements}

The authors would like to thank the Michigan Memorial Phoenix Energy Institute and the Graham Environmental Sustainability Institute for their continued support of graduate education. We also acknowledge the generous support of the U.S. Department of Energy through the UM 
High Pressure Lean Combustion Consortium and the DOE BES SISGR Program. Marco Ceze's continuous support is immensely appreciated.

\section{References}

${ }^{1}$ Dean, A. J., Penyazkov, O. G., Sevruk, K. L., and Varatharajan, B., "Autoignition of surrogate fuels at elevated temperatures and pressures," Proceedings of the Combustion Institute, Vol. 31, No. 2, 1 2007, pp. 2481-2488.

${ }^{2}$ Chevron, "Aviation fuels technical review," Tech. rep., 2006.

${ }^{3}$ Moses, C. A., Stavinoha, L. L., and Roets, P., "Qualification of sasol semi-synthetic jet a-1 as commercial jet fuel," Tech. Rep. SwRI-8531, 1997.

${ }^{4}$ Bloomberg, "Algae-powered jet proves biofuel in continental test," 2009.

5 "Jatropha jetliner: New zealands biofuel plane uses 50-50 blend," 2008.

${ }^{6}$ BBC, "Airline in first biofuel flight," 2008.

${ }^{7}$ Curran, H. J., Gaffuri, P., Pitz, W. J., and Westbrook, C. K., "A comprehensive modeling study of n-heptane oxidation," Combustion and Flame, Vol. 114, No. 1-2, 7 1998, pp. 149-177.

${ }^{8}$ Vasu, S. S., Davidson, D. F., Hong, Z., Vasudevan, V., and Hanson, R. K., "n-dodecane oxidation at highpressures: Measurements of ignition delay times and oh concentration time-histories," Proceedings of the Combustion Institute, Vol. 32, No. 1, 2009, pp. 173-180.

${ }^{9}$ Davidson, D. F., Herbon, J. T., Horning, D. C., and Hanson, R. K., "Oh concentration time histories in nalkane oxidation," International Journal of Chemical Kinetics, Vol. 33, No. 12, DEC 2001, pp. 775-783, PT: J; NR: 24; TC: 20; J9: INT J CHEM KINET; PG: 9; GA: 494BK.

${ }^{10}$ Shen, H.-P. S., Steinberg, J., Vanderover, J., and Oehlschlaeger, M. A., "A shock tube study of the ignition of n-heptane, n-decane, n-dodecane, and n-tetradecane at elevated pressures," Energy \& Fuels, Vol. 23, No. 5, 03/25/; 05/21/ 2009, pp. 2482-2489, doi: 10.1021/ef8011036; M3: doi: 10.1021/ef8011036.

${ }^{11}$ Dagaut, P., Reuillon, M., Cathonnet, M., and Voisin, D., "High-pressure oxidation of normal-decane and kerosene in dilute conditions from low to high-temperature," Journal de Chimie Physique et de Physico-Chimie Biologique, Vol. 92, No. 1, 1995, pp. 47-76, PT: J; TC: 21.

${ }^{12}$ Dagaut, P., Reuillon, M., Boettner, J.-C., and Cathonnet, M., "Kerosene combustion at pressures up to 40 atm: Experimental study and detailed chemical kinetic modeling," Symposium (International) on Combustion, Vol. 25, No. 1, 1994, pp. 919-926.

${ }^{13} \mathrm{He}$, X., Walton, S. M., Zigler, B. T., Wooldridge, M. S., and Atreya, A., "Experimental investigation of the intermediates of isooctane during ignition," International Journal of Chemical Kinetics, Vol. 39, No. 9, 2007, pp. 498-517, PT: J; TC: 1.

${ }^{14}$ Westbrook, C. K., Pitz, W. J., Herbinet, O., Curran, H. J., and Silke, E. J., "A comprehensive detailed chemical kinetic reaction mechanism for combustion of n-alkane hydrocarbons from n-octane to n-hexadecane," Combustion and Flame, Vol. 156, No. 1, 1 2009, pp. 181-199.

${ }^{15}$ Ciezki, H. K. and Adomeit, G., "Shock-tube investigation of self-ignition of n-heptane-air mixtures under engine relevant conditions," Combustion and Flame, Vol. 93, No. 4, 6 1993, pp. 421-433.

${ }^{16}$ Frenklach, M., "Reaction mechanism of soot formation in flames," Physical Chemistry Chemical Physics, Vol. 4, No. 11, 2002, pp. 2028-2037, PT: J; CT: 77th International Bunsen Discussion Meeting of the DeutscheBunsengesellschaft-fur-Physikalische-Chemie; CY: OCT 07-11, 2001; CL: BAD HERRENALB, GERMANY; TC: 193.

${ }^{17}$ Walton, S. M., "Ph.d. thesis: Experimental investigation of the auto-ignition characteristics of oxygenated reference fuel compounds," 2008.

${ }^{18}$ Walton, S. M., Wooldridge, M. S., and Westbrook, C. K., "An experimental investigation of structural effects on the auto-ignition properties of two c-5 esters," Proceedings of the Combustion Institute, Vol. 32, 2009, pp. 255-262, PT: J; NR: 19; TC: 1; J9: PROC COMBUST INST; PN: Part 1; PG: 8; GA: 427CG.

${ }^{19}$ Donovan, M. T., He, X., Zigler, B. T., Palmer, T. R., Wooldridge, M. S., and Atreya, A., "Demonstration of a free-piston rapid compression facility for the study of high temperature combustion phenomena," Combustion and Flame, Vol. 137, No. 3, 5 2004, pp. 351-365.

${ }^{20}$ Donovan, M. T., He, X., Zigler, B., Palmer, T. R., Walton, S. M., and Wooldridge, M. S., "Experimental investigation of silane combustion and particle nucleation using a rapid-compression facility," Combustion and Flame, Vol. 141, No. 4, 6 2005, pp. 360-370.

${ }^{21}$ He, X., Zigler, B. T., Walton, S. M., Wooldridge, M. S., and Atreya, A., "A rapid compression facility study of oh time histories during iso-octane ignition," Combustion and Flame, Vol. 145, No. 3, 5 2006, pp. 552-570.

${ }^{22}$ He, X., Donovan, M. T., Zigler, B. T., Palmer, T. R., Walton, S. M., Wooldridge, M. S., and Atreya, A., "An

15 of 16

American Institute of Aeronautics and Astronautics 
experimental and modeling study of iso-octane ignition delay times under homogeneous charge compression ignition conditions," Combustion and Flame, Vol. 142, No. 3, 8 2005, pp. 266-275.

${ }^{23}$ Walton, S. M., He, X., Zigler, B. T., Wooldridge, M. S., and Atreya, A., "An experimental investigation of iso-octane ignition phenomena," Combustion and Flame, Vol. 150, No. 3, 8 2007, pp. 246-262.

${ }^{24}$ Healy, D., Donato, N. S., Aul, C. J., Petersen, E. L., Zinner, C. M., Bourque, G., and Curran, H. J., "n-butane: Ignition delay measurements at high pressure and detailed chemical kinetic simulations," Combustion and Flame, Vol. 157, No. 8, 8 2010, pp. 1526-1539.

${ }^{25}$ Mehl, M., Vanhove, G., Pitz, W. J., and Ranzi, E., "Oxidation and combustion of the n-hexene isomers: A wide range kinetic modeling study," Combustion and Flame, Vol. 155, No. 4, 12 2008, pp. 756-772.

${ }^{26}$ Westbrook, C. K., "Chemical kinetics of hydrocarbon ignition in practical combustion systems," Proceedings of the Combustion Institute, Vol. 28, No. 2, 2000, pp. 1563-1577.

${ }^{27}$ McBride, B. J., Gordon, S., and Reno, M. A., "Thermodynamic and transport properties of individual species," Tech. Rep. NASA Technical Memorandum 4513, 1993.

${ }^{28}$ Wrmel, J., Silke, E. J., Curran, H. J., Conaire, M. S. ., and Simmie, J. M., "The effect of diluent gases on ignition delay times in the shock tube and in the rapid compression machine," Combustion and Flame, Vol. 151, No. 1-2, 10 2007, pp. 289-302. 